\title{
PROGRESS AT THE ISOTRACE RADIOCARBON FACILITY
}

\author{
ROELF P BEUKENS, DEBBIE M GURFINKEL, and HENRY W LEE \\ Isotrace Laboratory, University of Toronto \\ Toronto (Ontario) M5S 1A7 Canada
}

ABSTRACT. Since August 1984 over 100 samples have been analyzed. ${ }^{12} \mathrm{C},{ }^{13} \mathrm{C}$, and ${ }^{14} \mathrm{C}$ isotopes were measured after acceleration and all dates were corrected for natural and preparation-induced fractionation. A precision of better than $1.0 \%$ was obtained for samples 10,000 yr BP or less and these results were shown to be reproducible at precision levels as low as $0.3 \%$. An accuracy of better than $1.0 \%$ was demonstrated for the same age range by analyzing samples which were previously dated with the conventional technique. The machine background, measured on blank sample holders in a clean ion source, yielded a count rate equivalent of $0.015 \pm 0.007 \%$ modern.

\section{INTRODUCTION}

With the arrival of the General Ionex Corporation Tandetron in 1982 at the Isotrace Radiocarbon Facility of the University of Toronto, work was started to attain the following objectives:

1) The measurement of ${ }^{12} \mathrm{C},{ }^{13} \mathrm{C}$ and ${ }^{14} \mathrm{C}$ isotopes after acceleration, to allow correction for sample fractionation.

2) A precision and accuracy of better than $1.0 \%$ for samples $10,000 \mathrm{yr}$ BP or less.

3) A machine background of $0.1 \%$ of modern or less.

4) Low contamination preparation techniques for wood, charcoal, shell, groundwater carbonates and bone samples of ca $6 \mathrm{mg}$ carbon.

5) A fully automated data acquisition and machine control.

Following the commissioning in early 1984 of the automated data acquisition and machine control system, the stability and the transmission characteristics of the system elements were tested and many improvements were made. In particular, the machine fractionation was studied in detail and mass dependent effects were reduced significantly. The technical aspects of these improvements and the data acquisition and analysis procedures were recently discussed by Kieser et al (1986). By the middle of 1984 the measurements were started to demonstrate that our objectives had been met.

\section{OPERATION OF THE ISOTRACE RADIOCARBON FACILITY}

The distribution of 71 of the $100+$ dates that have been produced is shown in Figure 1 as a function of age and sample material. Most of these samples were submitted by the Geological Survey of Canada. Six groundwater carbonate samples were submitted by the National Hydrology Research Institute in Ottawa from samples collected at depths ranging to $600 \mathrm{~m}$ from a hydro-geochemical borehole. Parks Canada submitted four small twigs from the L'Anse aux Meadows Viking settlement in Newfoundland for high precision age determination. Several shell and steel samples were submitted as part of the Joint Physics and Archaeology teaching program at the University of Toronto. The Australian National University provided several calibration samples while our NBS Oxalic-I standards were fabricated from acetylene, provided by Meyer Rubin from the USGS.

Standard pretreatment techniques were adapted and carefully tested 

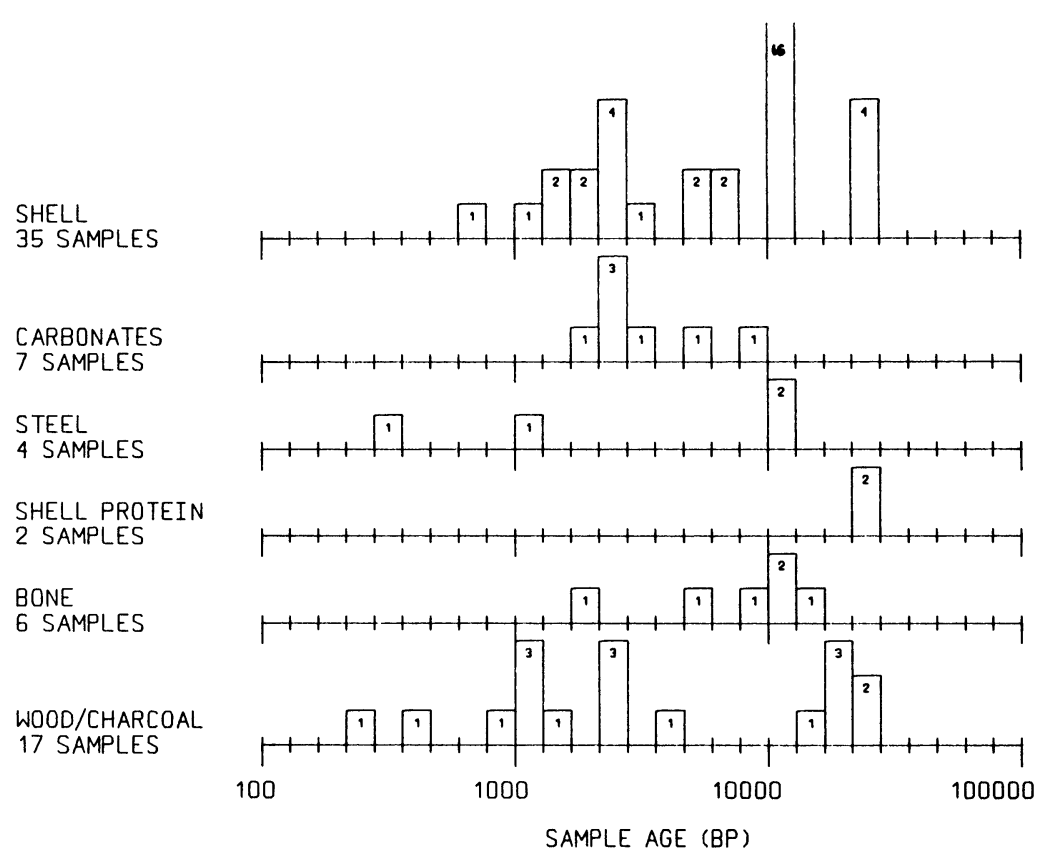

Fig 1. Histogram as a function of sample material and age of dates obtained in 1984 and 1985 obtained by the Isotrace Lab

for use with small samples (Gurfinkel, 1984). $\mathrm{CO}_{2}$, generated by closed ampule combustion or acid hydrolysis, is converted to acetylene via $\mathrm{Li}_{2} \mathrm{C}_{2}$ synthesis in a reaction bomb designed for 5 to $8 \mathrm{mg}$ carbon. Average yields of pretreatment and carbon content of the residue for all samples done to date are shown in Table 1. The minimum sample sizes, listed in Table 1, are currently recommended for old material, as contamination studies for samples $<5 \mathrm{mg}$ carbon have not been completed. For more recent material smaller samples have been used.

The acetylene is converted to graphitic material in a $1 \mathrm{kV}$ discharge as described by Beukens and Lee (1981). One major improvement, the

TABLE 1

Average yields and carbon content of sample pretreatment

\begin{tabular}{lccc}
\hline & $\begin{array}{c}\text { Yield } \\
(\%)\end{array}$ & $\begin{array}{c}\text { Recovered } \\
\text { carbon } \\
(\%)\end{array}$ & $\begin{array}{c}\text { Recommended min } \\
\text { sample size (mg) }\end{array}$ \\
\hline Bone collagen & $0.9-20$ & 43 & $1500-70$ \\
Wood lignin \& cellulose & 70 & 56 & 15 \\
Wood cellulose & 40 & 57 & 25 \\
Charcoal & 50 & 52 & 20 \\
Shell protein & 20 & 46 & 70 \\
Shell carbonate & 80 & 4 & 180 \\
Groundwater $\mathrm{BaCO}_{3}$ & & 6 & 100 \\
\hline
\end{tabular}


replacement of the RF discharge by an AC discharge, allows better control of the discharge and of the type of material being deposited. A typical acetylene sample, containing $4 \mathrm{mg}$ carbon, produces four machine-ready samples. Two are usually analyzed and the remaining two are used for archiving. The cracking process is strongly pressure-dependent and is limited to acetylene pressures of 11 to 5torr. The unused acetylene is currently discarded, limiting the conversion efficiency to ca 50\%. In addition, at the lower pressures, bubbles are deposited of a low conductance form of carbon which does not produce negative ions readily. After carefully removing these bubbles by gentle scraping with a clean scalpel, a machine ready sample contains from 200 to $300 \mu \mathrm{g}$ carbon. This is enough for two hours analysis, over which time a precision of $0.6 \%$ is obtained for modern material.

Our sample holder in the source has currently 7 positions which are filled with 2 machine setup samples, 2 NBS Oxalic-I standards, and 3 samples of unknown age. The analysis of the samples is performed under complete computer control and runs unattended for 10 hours after which the next samples are inserted. The system is continuously operated on a 24 hour basis for 2 to 3 weeks, after which the source is cleaned thoroughly. As two machine ready samples are usually measured for every sample, a throughput of 21 dates per week can be obtained at present.

\section{PRECISION, REPRODUCIBILITY, AND ACCURACY}

Figure 2 shows the precision obtained on the samples dated at Isotrace in 1984 and early 1985 . The objective of a precision of $1.0 \%$ or better for

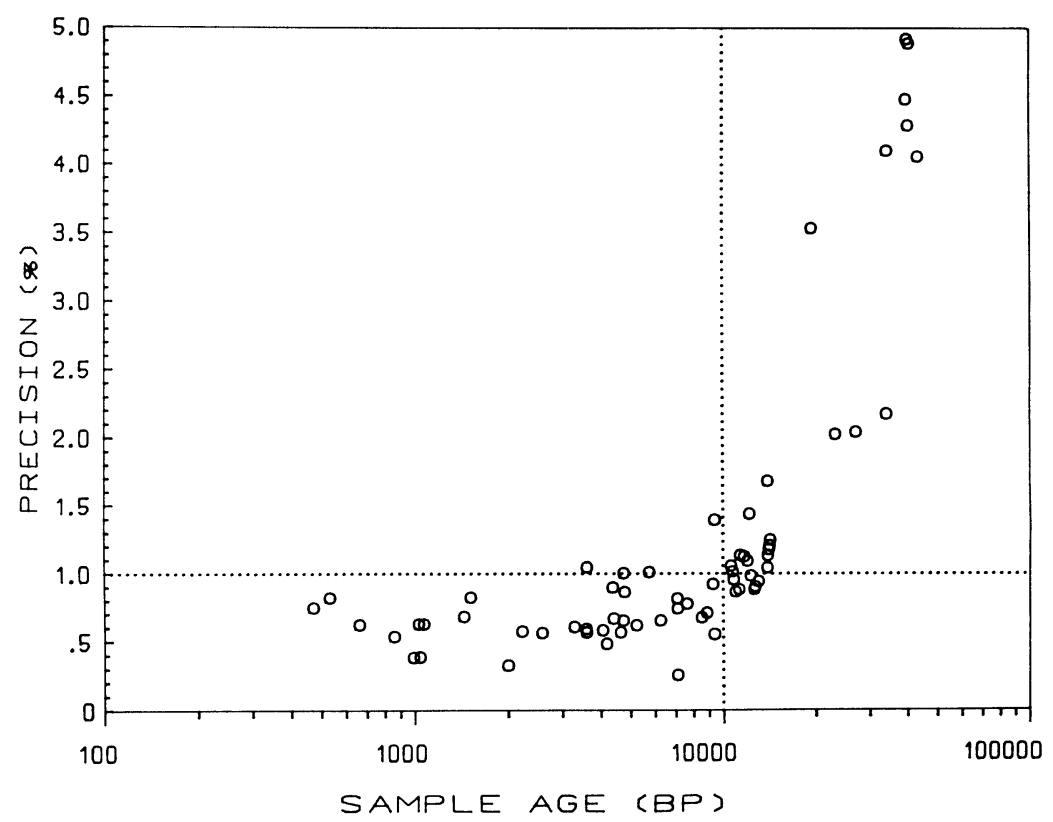

Fig 2. Precision obtained as a function of the age of samples dated in 1984 and 1985 by the Isotrace Lab 
TABLE 2

Reproducibility test

\begin{tabular}{lcccc}
\hline \multicolumn{1}{c}{ Date } & \# measurements & Age (BP) & Internal & External \\
\hline TO-25 & 15 & 2004 & \pm 26 & \pm 24 \\
TO-33 & 20 & 7108 & \pm 20 & \pm 20 \\
TO-118 & 4 & 990 & \pm 30 & \pm 22 \\
TO-119 & 4 & 1040 & \pm 30 & \pm 30 \\
\hline
\end{tabular}

samples of 10,000 yr bp or less is clearly met. The precision is calculated from all known random errors, $i e$, the ${ }^{14} \mathrm{C}$ counting errors and the errors in the ${ }^{12} \mathrm{C}$ and ${ }^{13} \mathrm{C}$ current measurements for the sample and the standards. To demonstrate that these are the only sources which contribute to the error, several samples were remeasured many times. This reproducibility test yields 2 independent estimates for the precision. The internal error on the average is calculated from the transmission of all known errors of each measurement. The external error is the most-likely-error on the average as estimated from the variance and includes the contribution of all random errors of known as well as unknown sources. The relative error in this estimate is approximated by $\sqrt{1 / 2 \mathrm{~N}}$ where $\mathrm{N}$ is the number of measurements. Table 2 shows that the external errors are the same as the internal errors. Therefore, at a precision level of $0.3 \%$, no other sources of errors contribute significantly to the precision than the counting and current measurement errors. While the precision and reproducibility are a test of the quality of the measurement, the accuracy is a test of the method, $i e$, the presence of systematic errors. The accuracy was measured in a relative way by analyzing samples which have been dated previously by conventional laboratories. Table 3 shows the analysis of 11 samples, prepared from wood, charcoal, shell, bone, and sucrose, provided by GSC and ANU. No background corrections have been applied to these results. As the AMS date reflects the age of a very small portion of the sample, while the conventional date represents the average sample age, the homogeneity of the sample is very important. Three clear outliers are present in this comparison which are most likely due to sample inhomogeneity. The first outlier (TO-27) is a piece of wood, dated by a number of conventional laboratories which are all in good

TABLE 3

Accuracy test

\begin{tabular}{|c|c|c|c|c|c|}
\hline \multirow{2}{*}{$\frac{\text { Date }}{\text { TO-25 }}$} & \multirow{2}{*}{$\frac{\text { Sample }}{\text { GB-82-11 }}$} & \multicolumn{2}{|l|}{ Age (yr BP) } & \multicolumn{2}{|c|}{ Conventional date } \\
\hline & & $2004 \pm 26$ & & $1950 \pm 50$ & GSC-3531 \\
\hline TO-23 & BS-77-362 & $4730 \pm 30$ & & $4600 \pm 60$ & GSC-2651 \\
\hline TO-28 & WB-100-66 & $6250 \pm 30$ & & $6150 \pm 60$ & GSC-2441 \\
\hline $\mathrm{TO}-27$ & FI-75-72-I & $23,280 \pm 160$ & & $25,200 \pm 260$ & GSC-1802 \\
\hline ТО-29 & $113 / 52$ & $4640 \pm 50$ & & $4660 \pm 60$ & GSC-2186 \\
\hline TO-51 & ANU-644 & $39,720 \pm 360$ & & $34,800 \pm 1800$ & ANU-644 \\
\hline TO-31 & SB-9.9.79(B) & $4180 \pm 40$ & & $3700 \pm 60$ & GSC-3043 \\
\hline TO-62 & RAB-83-12 & $10,810 \pm 80$ & & $11,000 \pm 90$ & GSC-3706 \\
\hline ТO-30 & BS-70-55 & $9350 \pm 40$ & & $9340 \pm 80$ & GSC-1496 \\
\hline TO-33 & BS-79-134 & $7108 \pm 20$ & & $6920 \pm 90$ & GSC-3055 \\
\hline TO-43 & ANU sucrose & $1.516 \pm .005$ & $x$ & $1.501 \pm .005$ & $\times$ modern \\
\hline
\end{tabular}


agreement with each other, so there is little doubt that our measurement is anomalous. The material we received was a remnant of this large sample. The second outlier (TO-51) is part of a large inhomogeneous charcoal sample (John Head, pers commun). The third outlier (TO-31) is a shell sample and the discrepancy in this case is not very surprising as our date was obtained on part of one shell from a sample of many shells. Regression analysis of the remaining samples yields a slope of $1.006 \pm 0.009$ and an offset of $-0.5 \pm 0.5 \%$ modern, indicating that the accuracy is better than $1.0 \%$.

\section{SOURCE AND SAMPLE CONTAMINATION}

Measurements of the machine background are shown in Table 4A. Direct cross-contamination in the source of one sample by another is avoided by properly designed sample holders but contamination of the whole source region is unavoidable. At least $90 \%$ of all sputtered ${ }^{14} \mathrm{C}$ is deposited somewhere in the source which is cleaned thoroughly every 2 to 3 weeks. The contribution of this contamination to the apparent age of an infinitely old sample was measured on blank aluminum sample holders. A clean source yielded a contamination of $0.015 \pm 0.007 \%$ modern, while a source that has been used continuously for more than two weeks yielded $0.035 \pm 0.007 \%$ modern. However, high purity graphite yielded a higher contamination of $0.130 \pm 0.009 \%$ modern. This could be due to actual ${ }^{14} \mathrm{C}$ in the graphite or, at least in part, to source hydrocarbons. Experiments supporting this last hypothesis have been described by Lee (1985).

Several background samples were measured many times in an attempt to determine the contamination contributed by sample preparation (Table

TABLE 4

A) Machine background measurements

\begin{tabular}{lcc}
\hline & $\%$ modern & Eqv age (BP) \\
\hline Effect of ${ }^{12} \mathrm{C}$ from tail & $0.007 \pm 0.002$ & $76,000 \pm 2,300$ \\
Clean source & $0.015 \pm 0.007$ & $71,000 \pm 3,700$ \\
Dirty source & $0.035 \pm 0.007$ & $65,000 \pm 1,600$ \\
High purity graphite & $0.130 \pm 0.009$ & $53,600 \pm 600$ \\
\hline
\end{tabular}

B) Contamination measurements

\begin{tabular}{lcc}
\hline \multicolumn{1}{c}{ Material } & \% modern & Eqv age (BP) \\
\hline Calcium carbide & $0.142 \pm 0.028$ & $52,700 \pm 1,600$ \\
Calcite crystal & $0.237 \pm 0.015$ & $48,600 \pm 500$ \\
Cylinder CO & $0.556 \pm 0.047$ & $41,700 \pm 700$ \\
Anthracite & $0.358 \pm 0.033$ & $45,200 \pm 700$ \\
High purity graphite & $0.513 \pm 0.034$ & $42,400 \pm 500$ \\
\hline
\end{tabular}

C) Oldest measured samples for different materials

\begin{tabular}{llcc}
\hline \multicolumn{1}{c}{ Material } & Sample & \% modern & Age (BP) \\
\hline Wood & TO-95 & $0.342 \pm 0.037$ & $45,610 \pm 860$ \\
Shell & TO-68 & $0.637 \pm 0.062$ & $40,620 \pm 780$ \\
Shell protein & TO-114 & $0.452 \pm 0.019$ & $43,370 \pm 330$ \\
Charcoal & TO-51 & $0.712 \pm 0.032$ & $39,720 \pm 360$ \\
\hline
\end{tabular}


4B). However, most materials demonstrated some degree of intrinsic contamination and the results represent limits only. The contribution by the production of solid graphitic samples by the dissociation of acetylene in a high voltage AC discharge was measured with acetylene, produced from technical grade calcium carbide. As the measured contamination is barely above the upper estimate of $0.13 \%$ modern for the machine background, this contribution is probably negligible. The contribution by the synthesis of acetylene was tested with $\mathrm{CO}_{2}$ produced by acid hydrolysis of a large calcite crystal. This crystal has some contamination along microfissures and requires a preleach of the finely pulverized calcite to reduce the contamination to the value shown in Table 4B. Thus, the results suggest a contribution of $<0.1 \%$ modern due to contamination by the acetylene synthesis. Anthracite and high purity graphite were used to study the contribution from the combustion. The lowest contamination was obtained after cleaning the sample surface by oxidation in air, while normally treated wood and shell-protein samples, submitted for dating, yielded the same or older dates (Table 4C). This indicates that surface contamination due to handling is a major source of the observed contamination. Combustion in an $\mathrm{O}_{2}$ flow and rejection of the $\mathrm{CO}_{2}$ from the surface could improve the results for graphite and anthracite samples.

As the results of the accuracy test in Table 3 have not been corrected for background, the good agreement in this comparison suggests that the actual contribution to contamination by sample preparation, is less than indicated by Table $4 \mathrm{~B}$ and that these measurements reflect, at least in part, the contamination of the samples.

\section{FRACTIONATION}

All three carbon isotopes are transmitted sequentially through the accelerator and measured for all samples. If $\mathrm{r}_{13}$ and $\mathrm{r}_{14}$ are the ${ }^{13} \mathrm{C} /{ }^{12} \mathrm{C}$ and ${ }^{14} \mathrm{C} /{ }^{12} \mathrm{C}$ ratios of a $1 \times$ modern sample with a $\delta^{13} \mathrm{C}=-25 \%$, the measured ratios for the standard are expressed as:

$$
\begin{gathered}
\mathrm{R}_{13}^{\mathrm{st}}=\mathrm{F}_{13} \times \mathrm{f}_{\mathrm{st}} \times \mathrm{r}_{13} \\
\mathrm{R}_{14}^{\mathrm{st}}=\mathrm{F}_{14} \times \mathrm{f}_{\mathrm{st}}^{2} \times \mathrm{r}_{14} \times \mathrm{A}
\end{gathered}
$$

For a sample with an unknown age $\mathrm{T}$ the measured ratios are expressed as:

$$
\begin{gathered}
\mathrm{R}_{13}=\mathrm{F}_{13} \times \mathrm{f} \times \mathrm{r}_{13} \\
\mathrm{R}_{14}=\mathrm{F}_{14} \times \mathrm{f}^{2} \times \mathrm{r}_{14} \times \operatorname{EXP}(-\mathrm{T} / 8033)
\end{gathered}
$$

$\mathrm{f}$ is the total sample fractionation which is the product of the natural fractionation $\mathrm{fn}$ and the preparation-induced fractionation $\mathrm{fp}$.

$\mathrm{F}$ is fractionation of ${ }^{13} \mathrm{C}$ or ${ }^{14} \mathrm{C}$ isotopes relative to ${ }^{12} \mathrm{C}$ due to the mass dependent transmission efficiency of the accelerator and sputter processes in the ion source.

$\mathrm{A}$ is the activity of the standard, normalized to a base of $\delta^{13} \mathrm{C}=-25 \%$. For NBS Oxalic-I,

$$
\mathrm{A}=\frac{1}{0.95} \times\left(\frac{1-0.025}{1-0.019}\right)^{2}=1.040 \times \text { modern }
$$


Eliminating the fractionations $\mathrm{f}$ and $\mathrm{F}$ from Equations 1 and 2 we get the simple age equation:

$$
\operatorname{EXP}(-\mathrm{T} / 8033)=\mathrm{A} \times \frac{\mathrm{R}_{14}}{\mathrm{R}_{14}^{\mathrm{st}}} \times\left(\frac{\mathrm{R}_{13}^{\mathrm{st}}}{\mathrm{R}_{13}}\right)^{2}
$$

The age $\mathrm{T}$ of the unknown sample is corrected for natural and preparation-induced fractionation to a base of $\delta^{13} \mathrm{C}=-25 \%$ and is expressed in conventional ${ }^{14} \mathrm{C}$ years. In this derivation assumptions have been made with respect to the fractionations $\mathrm{f}$ and $\mathrm{F}$.

In Equations $1 \mathrm{~b}$ and $2 \mathrm{~b}$, the fractionation for the ${ }^{14} \mathrm{C} /{ }^{12} \mathrm{C}$ ratio is taken to be the square of the fractionation for ${ }^{13} \mathrm{C} /{ }^{12} \mathrm{C}$. This is usually assumed to be correct for the natural fractionation $\mathrm{fn}$ but requires an explanation in the case of the preparation-induced fractionation fp. Figure 3 shows $\delta^{13} \mathrm{C}$ as a function of the percentage completion of a chemical reaction as a result of Rayleigh fractionation. The initial fractionation of $\delta^{13} \mathrm{C} \approx-17 \%$ of a cracked sample was determined experimentally by comparing the ${ }^{13} \mathrm{C} /{ }^{12} \mathrm{C}$ ratios with a homogeneous graphite sample. The solid line represents the total fractionation of the end product. The dashed curve is the differential curve and shows that the material that is being deposited becomes more and more enriched in the heavier isotope and $\delta^{13} \mathrm{C}$ attains a large positive value at $100 \%$ completion. If the end product can be homogenized, as in the case of a gas or liquid, $\delta^{13} \mathrm{C}$ follows the solid curve and no additional fractionation will be present if $100 \%$ completion is attained. If the end product is a solid, as is usual in AMS dating, $\delta^{13} \mathrm{C}$ follows the dashed curve. In our case we start at ca $30 \%$ completion, follow the dashed curve down to

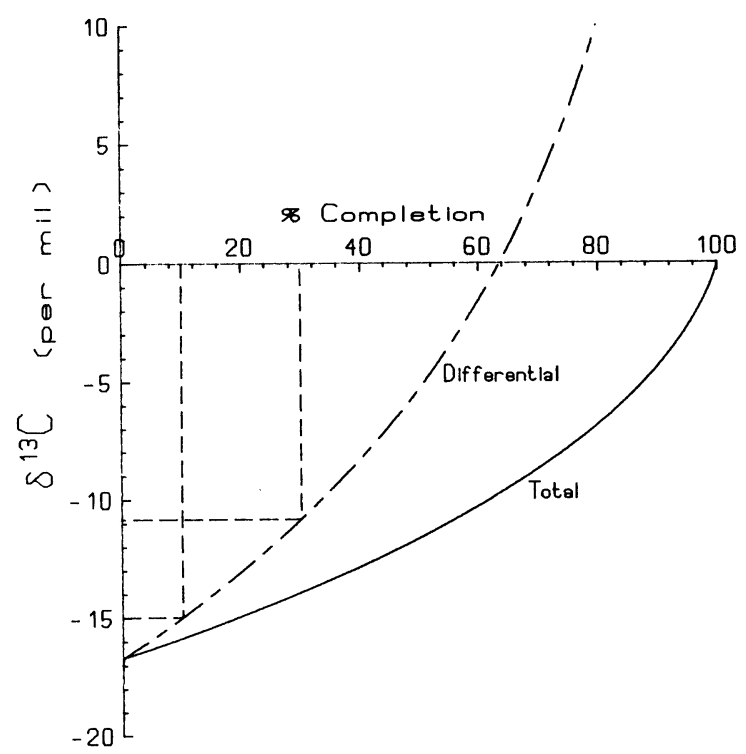

Fig 3. Total and differential Rayleigh fractionation curves, calculated for an initial $\delta^{13} \mathrm{C} \approx$ $-17 \%$ 
ca $10 \%$ completion where the measurement is stopped. The actual preparation-induced fractionation $\mathrm{fp}$ is then the average along that part of the dashed curve. Similar curves can be calculated for the ${ }^{14} \mathrm{C} /{ }^{12} \mathrm{C}$ ratio assuming a Rayleigh fractionation which is linear in mass. Calculations show that, if the initial fractionation is not very large, the fractionation remains approximately linear in mass anywhere along the dashed curve except close to the $100 \%$ completion point, where the material is strongly enriched in the heavier isotopes. The good agreement of the comparison in Table 3 indicates that the approximation is valid at a precision level of at least $1.0 \%$.

The machine fractionations $\mathrm{F}$ are assumed to be sample independent. The largest contributor to $\mathrm{F}$, the velocity-dependent stripping efficiency in the stripper gas, should be sample independent in a properly designed system. However, at higher precision other factors become important such as varying source emittance due to sample surface irregularities (Bedrich et al, 1983) or fractionation introduced by the sputtering process (Shimizu \& Hart, 1982). The first effect was minimized by using flat $3 \mathrm{~mm}$ diameter samples which are scanned under computer control to reduce cratering. The fractionation due to matrix effects was studied by measuring the $\delta^{13} \mathrm{C}$ of three samples obtained from the Centre des Faibles Radioactivités at Gifsur-Yvette. These samples were produced by the reduction of $\mathrm{CO}_{2}$ from NBS Oxalic-I on small iron pellets and contained a mixture of $2 \mathrm{mg}$ carbon and $9 \mathrm{mg}$ iron. An additional fractionation of $\delta^{13} \mathrm{C} \approx-25 \%$ was observed for these samples relative to our cracked NBS Oxalic-I. This fractionation was apparently generated by the presence of the iron as the removal of the iron by recombustion and cracking according to our standard procedure completely removed this fractionation.

\section{ACKNOWLEDGMENTS}

We wish to acknowledge the financial support of this work by the Natural Sciences and Engineering Research Council, Energy Mines and Resources of Canada, Environment Canada, and the University of Toronto. We also like to thank Henry Polach of the Australian National University, Weston Blake of the Geological Survey of Canada, Ursula Franklin of the Collegium Archaeometricum, University of Toronto, and our colleagues at the Isotrace Laboratory for their advice and support.

REFERENCES

Bedrich, W, Koch, B, Mai, H, Seidenkranz, U, Syhre, H and Voigtmann, R, 1983, Distortion of secondary ion extraction due to sample surface irregularities, in Benninghoven, $\mathrm{A}$, Giber, J, Laszlo, J, Riedel, M and Werner, H W, eds, Internatl conf on secondary ion mass spectrometry, 3rd, Proc: Springer series in chemical physics, v 19, p 81-87.

Beukens, R P and Lee, $\mathrm{H} \mathrm{W}, 1981$, The production of small carbon samples by RF dissociation of acetylene, in Kutschera, W, eds, Symposium on accelerator mass spectrometry, 2nd,
Proc: Argonne Natl Lab, p 416-425.

Gurfinkel, D M, 1984, ${ }^{14} \mathrm{C}$ sample preparation: Isotrace 1984 ann rept, p 5-30.

Lee, $\mathrm{H} \mathrm{W},(\mathrm{ms}), 1985$, Study of ${ }^{14} \mathrm{C}$ detection and dating using accelerator mass spectrometry: PhD dissert, Univ Toronto.

Kieser, W E, Beukens, R P, Kilius, L R, Lee, H W and Litherland, A E, 1986, Isotrace radiocarbon analysis-equipment and procedures, in Internatl conf on ionbeam analysis, $7 \mathrm{th}$, Proc: Nuclear Instruments \& Methods, v B15, p 718-721.

Shimizu, N and Hart, S R, 1982, Isotope fractionation in secondary ion mass spectrometry: Jour Appl Physics, v 53, no. 3, p 1303-1311. 